Anthropos: JurnalAntropologiSosialdanBudaya (Journal of Social and Cultural Anthropology)

6 (2) (2021): 172-180 DOI: https://doi.org/10.24114/antro.v6i2.18494

Anthropos: Jurnal Antropologi Sosial dan Budaya (Journal

of Social and Cultural Anthropology)

Available online http://jurnal.unimed.ac.id/2012/index.php/anthropos

\title{
Ritual Wulla Poddu Sebagai Model Resiliensi Masyarakat Marapu di Kampung Tarung dan Praiijing Sumba Barat
}

\author{
Wulla Poddu Ritual as Resilience Model of Marapu \\ Community in Tarung and Praiijing Villages, West Sumba
}

\author{
Berlian Rambu Pesi Kondi*, Rama Tulus Pilakoannu \& Izak Y. M. Lattu \\ Magister Sosiologi Agama, Fakultas Teologi, Universitas Kristen Satya Wacana, Indonesia
}

Diterima: 15 Juni 2020; Direview: 26 Juli 2020; Disetujui: 12 Agustus 2020

\begin{abstract}
Abstrak
Penelitian ini bertujuan untuk menganalisis ritual Wulla Poddu sebagai model resiliensi masyarakat Marapu di Kampung Tarung dan Praiijing Sumba Barat. Penulisan ini menggunakan teori resiliensi dan ritual serta liminalitas. Penelitian ini menggunakan pendekatan penelitian metode kualitatif deskriptif digunakan untuk memperoleh data yang mendalam berdasarkan pemahaman para informan. Hasil penelitian yang diperoleh adalah dalam berbagai tekanan yang dialami, masyarakat Tarung dan Praiijing sampai saat ini memiliki kemampuan untuk kembali dalam suatu keadaan seperti semula setelah mendapatkan tekanan dan kesulitan, hal ini disebut juga sebagai resiliensi. Masyarakat beresiliensi melalui ritual Wulla Poddu dapat bertahan dan tetap hidup hingga saat ini. Ritual Wulla Poddu kemudian mengikat masyarakat dalam satu kesatuan yang utuh. Melalui ritual Wulla Poddu resiliesi dibutuhkan untuk dapat bertahan ketika hidup dalam berbagai tekanan dan ketidakpastian. Tekanan dan ketidakpastian tersebut berasal dari pemerintah dalam memperoleh hak serta kewaijibannya dan juga berasal dari agama resmi (Islam dan Kristen) yang pada hakekatnya telah memiliki kepercayaan terhadap Marapu sebagai Tuhannya. Dalam hal ini ritual Wulla Poddu menjadi ritual yang bersifat terbuka di dalam ketidakpastian yang terjadi.
\end{abstract}

Kata Kunci: Resiliensi, Ritual Wulla Poddu, Marapu, Agama Kristen, Agama Islam.

\begin{abstract}
The purpose of this research is to analyze the Wulla Poddu ritual as Resilience Model of Marapu community in Tarung and Praiijing villages, West Sumba. The theories used are resilience, ritual, and liminal.The research approach is descriptive qualitative method. The deep data is obtained based on the understanding of the community informants. The results of the research showed that under a lot of pressures, Tarung and Praiijing community had the ability to return to the beginning of the situation called resilience in the form of Wulla Poddu ritual of Marapu belief. Marapu is considered as the intermediate spirit that had the power to raise the feeling of the community through Wulla Poddu ritual events. The Wulla Poddu Ritual bound the community to be one unity without status and religious differences, and returned to live their life as the beginning and even better than before. The pressure and uncertainty came from the government in obtaining rights, responsibility, and official religions (Islam and Christian) where the fact shows that they have a belief in Marapu as their God. In this case, the Wulla Poddu becomes an open ritual of uncertainty.
\end{abstract}

Keywords: Resilience, Wulla Poddu Ritual, Marapu, Christian, Islam.

How to Cite: Kondi, B.R.P., Pilakoannu R.T. \& Lattu, I.Y.M. (2021). Ritual Wulla Poddu Sebagai Model Resiliensi Masyarakat Marapu di Kampung Tarung dan Praiijing Sumba Barat. Anthropos: Jurnal Antropologi Sosial dan Budaya (Journal of Social and Cultural Anthropology) 6(2): 172-180.
*Corresponding author:
E-mail: berlianrambupesikondi@gmail.com 


\section{PENDAHULUAN}

Ritual Wulla Poddu merupakan suatu ritual yang dilaksanakan oleh masyarakat Marapu yang merupakan suatu kepercayaan lokal masyarakat Sumba (Wellem, 2004). Marapu adalah suatu sistem kepercayaan yang merupakan suatu bentuk dari kebudayaan yang diterima tanpa sadar dan proses pewarisannya dilakukan melalui komunikasi dan peniruan dari generasi ke generasi berikutnya (Palekahelu, 2010). Sebagai agama tidak resmi kepercayaan Marapu masih tetap bertahan di wilayah perkotaan Waikabubak, Sumba Barat. Masyarakat tersebut di antaranya adalah masyarakat di Kampung Tarung dan Kampung Praiijing yang terdiri dari berbagai suku di dalamnya. Hal ini menyebabkan masyarakat Marapu berada dalam keadaan harus hidup dan berinteraksi dengan berbagai penganut agama resmi seperti Islam dan Kristen. Pada kenyataannya agama resmi tersebut dalam menjalankan misi agamanya, sasarannya adalah masyarakat yang belum memiliki agama yang belum diakui seperti Marapu. Tekanan mulai dirasakan oleh masyarakat Marapu yang pada hakekatnya telah memiliki kepercayaan terhadap Marapu sebagai Tuhannya.

Dalam berbagai tekanan yang dialami yaitu berbagai permasalahan yang mengancam keberlangsungan hidup masyarakat Kampung Tarung dan Praiijing dapat dilihat dari pihak pemerintah dan keagamaan. Masyarakat khususnya yang masih menganut kepercayaan Marapu didorong untuk masuk ke dalam agama yang mendominasi wilayah tersebut. Maka Masyarakat Tarung dan Praiijing sampai saat ini memiliki kemampuan untuk kembali dalam suatu keadaan seperti semula setelah mendapatkan tekanan dan kesulitan yang disebut resiliensi (Walker et al., 2004). Resiliensi adalah kapasitas sistem untuk menyerap gangguan dan menata ulang saat mengalami perubahan sehingga tetap mempertahankan fungsi, struktur, identitas, dan menerima yang sama dasarnya (Walker et al., 2004).

Untuk itu dalam mempertahankan berbagai nilai dalam masyarakat Kampung Tarung dan Praiijing maka resiliensi menawarkan kemampuan untuk meninjau ulang dengan lebih baik bagaimana masyarakat Marapu dapat terus menyesuaikan diri untuk mengubah informasi, hubungan, tujuan, ancaman, dan faktor lainnya agar beradaptasi dalam menghadapi perubahan dan ketidakpastian terutama perubahan potensial tersebut yang bisa menghasilkan hasil negatif (Linkov \& Palma-Oliveira, 2017). Resiliensi dibutuhkan untuk mengatasi berbagai ancaman dari luar, sehingga ketahanan dan keamanan dapat terjadi (Linkov \& Palma-Oliveira, 2017)

Dalam hal ini pada masyarakat Kampung Tarung dan Praiijing dalam menghadapi berbagai tekanan yang dialaminya terdapat sebuah ritual yang membuat masyarakat dapat bertahan atau beresiliensi. Seperti Masyarakat Dayak Meratus khususnya yang beragama Kristen, yang berada di Desa Loksado atau yang biasa disebut "Dayak Bukit" daerah Kalimantan secara umum mengalami beberapa tekanan sosial. Terdapat ritual Seputar Hutan dan Ladang Sebagai Daya Lenting atau resiliensi Masyarakat Dayak Meratus di Loksado (Pilakoannu, 2017). Demikian pula pada masyarakat Marapu di Kampung Tarung dan Praiijing dapat bertahan dan beresiliensi melalui ritual Wulla Poddu.

\section{METODE PENELITIAN}

Penelitian ini menggunakan metode kualitatif. Metode kualitatif adalah penelitian yang bermaksud untuk memahami apa yang dialami oleh subjek penelitian yaitu masyarakat di Kampung Tarung dan Praiijing, misalnya perilaku masyarakat, persepsi masyarakat, motivasi masyarakat, tindakan yang biasanya dilakukan di Kampung Tarung dan Praiijing, dan lain-lain. Secara holistik dan 
dengan cara deskripsi dalam bentuk katakata dan bahasa adat "bahasa Loli" dalam konteks Kampung Tarung dan Praiijing (Moleong, 1991).

Jenis dan metode penelitian kualitatif digunakan untuk memperoleh data yang mendalam berdasarkan pemahamanpemahaman para informan. Dalam hal ini, informan yang dimaksudkan adalah kepala suku atau Rato Kampung Tarung dan Praiijing, masyarakat Marapu Kampung Tarung dan Praiijing, masyarakat Kristen dan Islam di sekitar Kampung Tarung dan Praiijing (Creswell, 2010).

Penelitian di Kampung Tarung dan Praiijing, kabupaten Sumba Barat ini dilakukan menggunakan teknik pengumpulan data Observasi dan wawancara. Melalui observasi terhadap situasi dan kondisi di Kampung Tarung dan Praiijing, untuk dapat mempelajari perilaku dan makna dari masyarakat (Sugiyono, 2007). Melalui wawacara yang dilakukan maka akan diperoleh data secara langsung dari narasumber, terhadap pihak yang dinilai dapat memberikan informasi dan data akurat. Narasumber tersebut adalah Rato (kepala suku) Kampung Tarung dan Praiijing, Masyarakat Marapu Kampung Tarung dan Kampung Praiijing, masyarakat Islam dan Kristen disekitar Kampung Tarung dan Praiijing (Moleong, 1991).

Untuk menganalisa data, maka dibutuhkan beberapa hal yaitu mereduksi data. Reduksi data berarti menggolongkan, memilih berbagai informasi dari wawancara dan observasi yang dilakukan di Kampung Tarung dan Praiijing agar dapat memperoleh kesimpulan akhir. Penyajian data dilakukan setelah mereduksi data, untuk memberikan suatu pemahaman singkat mengenai ritual Wulla Poddu dan permasalahan yang terjadi pada masyarakat Kampung Tarung dan Praiijing. Sehingga dapat mempermudah penulis dalam menganalisis data. Setelah mereduksi data dan menyajikan data maka bagian yang terakhir adalah menarik sebuah kesimpulan bahwa ritual Wulla Poddu dapat menjadi model resiliensi pada masyarakat Kampung Tarung dan praiijing. Sehingga dapat menjawab permasalahan tulisan ini (Sugiyono, 2007).

\section{HASIL DAN PEMBAHASAN Tahapan Ritual Wulla Poddu}

Ritual Wulla Poddu apabila diartikan maka Wulla berarti bulan dan Podu berarti pahit, jadi Wulla Poddu berarti bulan pahit. Oleh masyarakat Loli Wulla Poddu dapat dimaknai sebagai bulan suci, keramat. Wulla Poddu sebagai bulan suci masyarakat Marapu, memiliki aturan yang harus diikuti oleh seluruh orang Loli. Wulla Poddu pada Kampung Tarung dan Praiijing yang ada di Sumba Barat dilaksanakan sejak bulan mati hingga bulan purnama pada setiap bulan Oktober hingga November. Kampung Tarung sebagai salah satu Kampung adat yang menjadi salah satu objek wisata berada pada Kecamatan Loli, Kelurahan Soba Wawi. Suku-suku yang terdapat di Kampung Tarung yaitu suku Uma Rato, Uma Mawinne, Uma Ndara, Uma Wara. Berikutnya Kampung Praiijing merupakan sebuah Kampung adat atau ritus yang terletak di Kecamatan Kota Waikabubak. Terdapat berbagai suku yaitu suku Wola Atas, Wola Bawah, Katoda Dongu, Kumbea, Weemapedi, Wailawa, Modo, Waijewa, Kanabi, Waikarara Umbu Metti, Ruttuku Dangu Bii Kaka.

Ritual sebagai kekuatan religius yang tidak lain adalah perasaan dalam diri setiap individu yang dipancing oleh kolektivitas (Durkheim, 2011). Seperti ritual Mangejing, ritual Wulla Poddu merupakan tindakan atau perilaku religius yang dilakukan berulang-ulang untuk mengungkapkan nilai-nilai yang dianut masyarakat tersebut secara kolektif, (Djoru, 2017). Dalam ritual Wulla Poddu, masyarakat tidak dapat terlepas dari berbagai simbol kebudayaan yang melekat kepadanya sebagai suatu kesatuan yang memiliki kekuatan membangkitkan 
kekuatan dan semangat masyarakat. Berbagai ritual dan simbol yang digunakan oleh masyarakat Marapu dalam berbagai ritual kehidupannya.

Ritus berkaitan erat dengan masyarakat, yang dilakukan untuk mendorong orang-orang melakukan dan menaati tatanan sosial tertentu (Winangun, 1991). Ritus memberikan motivasi dan nilai pada tingkat yang paling dalam. Oleh sebab itu, ritus mempunyai peran dalam masyarakat, antara lain: menghilangkan konflik, mengatasi perpecahan dan membangun solidaritas masyarakat, menyatukan prinsip yang berbeda-beda dan memberi motivasi serta kekuatan baru untuk hidup dalam kehidupan masyarakat sehari-hari (Winangun, 1991). Demikian halnya berbagai ritual yang terdapat dalam kebudayaan masyarakat Marapu di Kampung Tarung dan Kampung Praiijing memiliki peran yang sangat penting bagi keberlangsungan hidup masyarakat. Ritual dapat dipakai sebagai sarana untuk dapat bertahan hidup dalam suatu perubahan hidup.

Ritual itu sendiri adalah sebuah strategi atau cara untuk bertindak "the way of acting" yang berbeda dalam kehidupan sehari-harinya, karena sense of ritual "tindakan di luar kewajaran" yang tertanam dalam kehidupan masyarakat (Bell, 1997). Selanjutnya pada ritual Ta'no yaitu ritual perlawanan masyarakat Oenbit di Timor Tengah Utara terjadi pergeseran makna (Taka, 2016). Ritual ini pada awalnya merupakan ritual kutukan akan tetapi menjadi ritual penolong masyarakat Oenbit untuk mendapatkan kembali tanah ulayat mereka yang telah di rampas (Taka, 2016). Oleh karena itu maka dapat dikatakan bahwa ritual memiliki suatu kekuatan yang mampu membangkitkan semangat dan kehidupan masyarakat.

Dengan demikian, dapat dikatakan bahwa dalam Ritual Wulla Poddu pada masyarakat Kampung Tarung dan Praiijing merupakan suatu ritual yang dapat menguatkan masyarakat ketika berada dalam suatu tekanan baik itu secara sosial maupun agama dan kebudayaan.

Pada ritual Wulla Poddu terdapat beberapa tahapan (Sutomo, 2014). Berikut tahap pelaksanaan ritual Wulla Poddu ini. Tahap yang pertama adalah tahap Patomani Li'i Ama Wolla Ama Rawi yang berarti penyampaian suara kepada yang Ilahi kepada kedelapan suku. Pada awal ritual ini, masyarakat selalu mempasrahkan dirinya kepada sang Ilahi dan mempunyai kekuatan untuk menjalaninya (Pilakoannu, 2017). Hal penting yang berkenaan dengan kehidupan masyarakat selalu dikaitkan dengan kuasa Ama wola Ama Rawi yang berarti "Sang Ilahi" untuk ikut terlibat di dalamnya. Tahap ini berisi permohonan ijin masyarakat Kampung kepada sang Ilahi yang dipimpin oleh Rato "kepala suku".

Tahap kedua adalah tahap Toba Wano yang berarti pembersihan Kampung. Tahap ini berisi pembersihan diri setiap masyarakat untuk memasuki Wulla Poddu ditandai dengan berkumur air dan mengelap lidahnya dengan daun kelapa.

Tahap ketiga adalah tahap deke kawuku yang berarti mengambil simpul. Pada tahap ini, Rato mengambil simpul yang disimpan di dalam gua dan menyimpan simpul yang baru untuk Wulla Poddu ditahun depan. Sementara rombongan dan Rato yang lainnya menanti di Kampung sambil doa berupa nyanyian syair bersahut-sahutan. Setelah setibanya Rato di Kampung dari gua, dilaksanakan penyerahan simpul kepada semua suku yang akan melaksanakan Wulla Poddu. Setelah itu, maka dilakukan lagi penyembelihan hewan persembahan. Pada setiap ritual yang dilakukan masyarakat berupaya untuk menyampaikan pesanpesan yang terkandung di dalam setiap aktivitas ritualnya, demikian halnya masyarakat Kampung Tarung dan Praiijing berusaha berkomunikasi dengan Yang Maha Pencipta melalui Marapu. Ritual 
dapat dipakai sebagai sarana untuk dapat bertahan hidup dalam suatu perubahan hidup (Bell, 1997).

Tahap keempat tahap Kaleisunga yang berarti persekutuan. Disampaikan undangan kepada seluruh masyarakat Loli baik yang ada di dalam Kampung maupun yang ada di luar Kampung, baik yang masih Marapu maupun masyarakat suku yang telah berpindah agama melalui RatoRato disetiap Kampung untuk mempersiapkan diri ikut berpartisipasi dalam pelaksanaan ritual. Pada saat hendak melaksanakan ritual Wulla Poddu secara tidak langsung mengisyaratkan kepada semua masyarakat yang memiliki uma kalada di Kampung Tarung dan Praiijing apapun agamanya dan dimanapun ia tinggal untuk harus kembali ke Kampung membawa berbagai bahan pangan seperti ayam, beras, kopi, gula dan lain sebagainya guna mempersiapkan Wulla Poddu. Jadi dapat dikatakan melalui Ritual Wulla Poddu berbagai masayarakat dalam suku-suku yang melaksanakan Wulla Poddu disatukan kembali dalam rumah besar dalam sukunya. Interaksi ritual membutuhkan banyak unsur-unsur dimana terdapat suatu individu atau kelompok individu yang berkumpul ditempat yang sama, membatasi diri dengan pihak luar, memutuskan pusat perhatian mereka pada objek atau kegiatan yang dilakukan bersama dan melalui hal ini mereka berbagi suasana hati atau pengalaman emosional yang melekat.

Tahap kelima adalah tahap Mana'a yang berarti makan bersama. Tahap ini berisi persembahan hewan kepada sang Marapu dan Pencipta pada malam hari sebelum pesta tarian, nyanyian dan makan bersama sebagai malam puncak. Pada tahap ini dimulai dengan ditandai dengan berkumur air. Setelah itu maka akan dilaksanakan doa-doa oleh Rato yang berisi harapan agar mendapatkan hasil panen yang baik, masayarakat dapat dihindarkan dari segala kekacauan dan mala petaka, menjaga keutuhan suku-suku yang ada dan supaya Wulla Poddu dapat terlaksana dengan baik. Ketika masyarakat berkumpul dalam suatu kebersamaan di Kampung Tarung dan Praiijing maka segala macam perbedaan status sosial, diskriminasi, dendam, dan berbagai perbedaan lainnya harus ditinggalkan. Masyarakat menjadi satu kesatuan di dalam ritual Wulla Poddu dalam hal ini yang dimasksudnya adalah bahwa seluruh masyarakat memiliki kedudukan yang sama. Kebersamaan ini ditandai dengan makan bersama oleh seluruh masyarakat Kampung. Juga melalui ritual ini, seluruh anggota masyarakat Kampung Tarung dan Praiijing kembali diundang dipersatukan pada rumah besar setiap suku yang ada pada kedua Kampung tersebut. Ritual atau sistem sosial yang lebih mengandung konsep-konsep kekerabatan dalam bingkai satu totalitas (Taka, 2016).

Tahap keenam adalah tahap Lodo Kalango yang berarti hari kegilaan. Pada tahap ini merupakan tahap puncak Wulla Poddu yang dimulai dari pagi. Masyarakat bersama dengan semua Rato yang melaksanakan Wulla Poddu akan dipanjatkan doa dalam nyayian syair sebagai rasa ungkapan syukur kepada Pencipta karena semua proses adatnya sudah dapat berjalan dengan baik selama satu bulan ini. Pada masa ini masyarakat memasuki masa liminalitas (Winangun, 1991). Liminalitas yang merupakan sebuah jembatan penghubung yang tidak berstruktur, bersifat transisi dan merupakan pencerminan dari pandangannya mengenai upacara dan agama sebagai suatu sistem yang bersifat formatif dan reflektif, dalam hal ini masyarakat Marapu di Kampung Tarung dan Praiijing pun mengalami liminalitas dalam ritual Wulla Poddu (Winangun, 1991). Dengan adanya liminalitas maka, upacara Wulla Poddu sebagai satu dasar terjadinya proses transformasi, juga bersamaan dengan itu membangkitkan kembali berbagai kategori lama yang 
bersifat struktural berfungsi sebagai pusat kekuatan pendorong dalam berbagai kegiatan, bagi penciptaan bentuk-bentuk baru dari konsep-konsep yang bersifat struktural. Masyarakat berada dalam suatu keadaan liminal yang berfungsi untuk memberikan kestabilan di dalam kehidupan masyarakat.

\section{Kebijakan Pemerintah terhadap Masyarakat Marapu Kampung Tarung dan Praiijing.}

Dari pihak pemerintah, terdapat pengelompokan agama resmi dan agama tidak resmi (agama asli masyarakat Indonesia, salah satunya adalah Marapu) (Samiyono, 2010). Agama yang diakui adalah agama Kristen, Katolik, Islam, Khong chu "Confusius", Hindu, Budha hal ini terdapat pada Pasal 1 Undang-Undang No. 1/PNPS/1965. Sedangkan berbagai kepercayaan termasuk kepercayaan Marapu dikelompokkan ke dalam agama yang tidak diakui oleh negara. Pengelompokan ini menimbulkan terjadinya diskriminasi di dalam masyarakat dalam pembatasan hak masyarakat, terutama dalam hal beragama dan memperoleh pendidikan formal.

Sehingga dalam Putusan MK RI Nomor 97/PUU-XIV/2016 mengenai "Penghayat kepercayaan" berisi pemberian hak kepada pada penganut agama tidak resmi diantaranya adalah Marapu untuk mengisi kolom agama pada Kartu Keluarga dan Kartu Tanda Penduduk sebagai Penghayat Kepercayaan (Bo'a \& Sri, 2019). Hal ini mengakibatkan masyarakat mendapatkan hak yang sama dengan keenam agama resmi di Indonesia meskipun sebagai suatu penghayat kepercayaan bukan agama. Akan tetapi, putusan ini hanya berlaku pada proses administrasi kependudukan tidak pada pendidikan formal. Anak didik harus mengisi kolom agama pada saat pendaftaran sekolah untuk mendapatkan mata pelajaran agama pada saat sekolah sejak Sekolah Dasar (SD). Maka dengan demikian dapat dikatakan bahwa permasalahan diskriminasi dan tekanan yang terjadi di Kampung Tarung dan Praiijing di Sumba Barat belum selesai.

Dari pihak keagamaan terdapat beberapa tekanan yang dirasakan oleh masyarakat Marapu di Kampung Tarung dan Praiijing. Dalam tekanan yang dirasakan oleh masyarakat maka yang terjadi adalah masyarakat Kampung Tarung dan Praiijing di dalam kepercayaan Marapu dianggap sebagai orang-orang kafir dan penyembah berhala, masyarakat dianggap sebagai dukun, masyarakat dianggap sebagai Suanggi (makluk halus di daerah Timur Indonesia), dianggap sebagai orang yang brutal, suka meminta minta bahkan secara kasar, masyarakat Marapu juga dianggap sebagai orang yang bodoh dalam arti memiliki SDM rendah. Sehingga dalam pemahaman yang demikian, masyarakat Marapu pada umumnya termasuk masyarakat Marapu di Kampung Tarung dan Praiijing seringkali menjadi objek berbagai agama termasuk agama Kristen dan Islam dalam penginjilan dan dakhwa. Masyarakat Marapu dianggap sebagai sekelompok masyarakat yang harus diselamatkan, untuk itu dalam segala keterbatasannya mereka harus diinjili dan didakhwa.

Dalam bidang pemerintahan dan keagamaan, pendidikan dianggap sebagai bagian masyarakat yang harus diperjuangkan dalam menikmati dunia pendidikan dalam berbagai program yang salah satunya meningkatkan SDM dan salah satu program pengentas kemiskinan. Untuk itu masyarakat Marapu Kampung Tarung dan Praiijiing didorong untuk menikmati dunia pendidikan bekerja sama dengan lembaga keagamaan untuk harus memiliki agama yang resmi sebagai salah satu syaratnya dalam mengisi kolom agama pada Raport siswa. Selain itu juga hak dan kewajiban dalam mendapatkan kartu identitas yaitu KTP harus memiliki agama yang resmi. 
Selain itu, dalam berbagai kebijakan yang diputuskan oleh pemerintah, masyarakat Marapu seringkali hanya mengikuti kebijakan yang ada. Putusan dan kebijakan ini dibuat tanpa adanya pertimbangan dari masyarakat yang menganut kepercayaan Marapu. Sehingga masyarakat Marapu di Kampung Tarung dan Praiijing menjadi masyarakat yang kaku dan tidak bebas dalam memperoleh hak dan kewaijibannya. Untuk itu maka terdapat strategi berbasis risiko dan berbasis resiliensi pada poin yang kedua meninjau kembali suatu sistem yang lemah dan mengidentifikasi kebijakan yang bisa mengurangi atau menyelesaikan masalah (Linkov \& Palma-Oliveira, 2017).

Masyarakat Marapu di Kampung Tarung dan Praiijing tidak dapat menghindari konsekuensi negatif yang terjadi. Sebagai suatu kumpulan masyarakat yang bermukim di tengahtengah perkotaan, masyarakat Marapu tidak dapat melakukan hal-hal untuk menghindari hal yang menimpa dirinya, masyarakat hanya dapat menghadapi permasalahannya dan berusaha bertahan terhadap kenyataan yang dialami.

Ritual Wulla Poddu Sebagai Suatu Model Resiliensi masyarakat Marapu Kampung Tarung dan Praiijing.

Terhadap keadaan yang dialami oleh masyarakat di Kampung Tarung dan Praiijing Sumba Barat. Terdapat strategi berbasis risiko dan berbasis resiliensi Aspek utama yang terdapat di dalamnya adalah mengenai bagaimana menilai dan memahami ketidakpastian dan bagaimana menilai hasil dari kejadian berbahaya dan untuk menilai hasilnya. Analisis resiliensi memberikan suatu kemampuan dasar untuk mengurangi bahaya yang terjadi, disamping itu dapat membantu suatu sistem tersebut untuk pulih dengan baik ke fungsi penuh secepat dan seefisien mungkin (Linkov \& Palma-Oliveira, 2017). Berbagai tekanan yang dialami oleh masyarakat di Kampung Tarung dan
Kampung Praiijing sebagian besar berasal dari pihak pemerintah dan keagamaan. Untuk dapat bangkit dari berbagai kesulitan dan tekanan hidup yang dialami, maka masyarakat membutuhkan resiliensi, (Aisha, 2014). Demikian halnya yang terjadi pada masyarakat Marapu dalam berbagai tekanan, ancaman dan ketidakpastian yang dialaminya selalu membutuhkan resiliensi. Salah satu hal yang mempengaruhi resiliesnsi adalah religiusitas (Aisha, 2014). Masyarakat tetap bertahan dalam kepercayaan Marapu dikarenakan nilai-nilai dalam kepercayaannya yang masih tertanam. Masyarakat menggunakan emosi positifnya yang tertanam dalam kepercayaan Marapu untuk kembali dalam keadaan semula. Emosi positif ini didapatkan melalui berbagai ritual di Kampung Tarung dan Praiijing. akan tetapi ritual yang paling besar di kedua Kampung tersebut adalah ritual Wulla Poddu.

Ketika masyarakat mengalami suatu masalah antar individu dan kelompok maka melalui sebuah ritual segala masalah yang terjadi dapat dipulihkan dan terselesaikan (Durkheim, 2011). Secara sosial, emosi positif yang ditemukan dalam pengalaman dan dengan demikian penerapan teori interaksi ritual memberikan alternatif untuk pendekatan kelangkaan atau pembebasan (Collins, 2004). Sehingga setelah ritual yang dilakukan masyarakat yang mengalami masalah, menjalani kehidupannya seperti sedia kala tanpa masalah.

Melalui tradisi ini maka sesuai dengan peran ritus itu sendiri masyarakat Marapu dalam Kampung Tarung dan Praiijing dalam ritus Wulla Poddu mempunyai peran dalam masyarakat (Durkheim, 2011), antara lain: menghilangkan konflik, mengatasi perpecahan dan membangun solidaritas masyarakat, menyatukan prinsip yang berbeda-beda dan memberi motivasi serta kekuatan baru untuk hidup dalam kehidupan masyarakat sehari-hari. Hal ini 
membuat masyarakat tidak hanya sembuh dari keadaan yang dialami akan tetapi seringkali dapat bangkit kembali bahkan lebih kuat dari pada sebelumnya (Grotberg, 2003). Demikian halnya masyarakat Marapu melalui berbagai ritualnya tetap hadir sebagai salah satu kepercayaan sampai saat ini.

Dalam menghadapi kehidupannya ketika berada dalam titik terendah kehidupan. Seperti diskriminasi, tekanan sosial religius, ekonomi dan politik yang dapat mengakibatkan masyarakat Marapu berada pada kondisi yang buruk. Untuk itu, sang Ilahi di dalam Ritual Wulla Poddu hadir agar setiap kelompok individu mampu bangkit kembali (bouncing back) dan menemukan cara untuk mengatasi kondisi kritis yang dialaminya (Reivich \& Shatte, 2002). Selain berguna untuk mengatasi hambatan-hambatan yang dialami, juga berguna untuk dapat melindungi, dan membela diri sendiri dengan tujuan untuk mendapatkan hidup yang bermakna dan tujuan yang baru dari hidupnya.

\section{SIMPULAN}

Melalui serangkaian ritual Wulla Poddu, Marapu dianggap sebagai roh perantara antara masyarakat dengan Pencipta yang tidak dapat disebutkan namanya serta memiliki kekuatan yang dapat membangkitkan perasaan masyarakat. Berbagai simbol kebudayaan menjadi sebuah sarana untuk membawa masyarakat ke dalam suatu pemenuhan kekuatan kolektif dalam kepercayaan Marapu. Pada akhirnya dapat dikatakan bahwa ritual Wulla Poddu merupakan bagian penting dalam masyarakat Marapu di Kampung Tarung dan Praiijing untuk dapat beresiliensi hingga saat ini.

Ketika masyarakat Kampung Tarung dan Praiijing berada dalam permasalahan yang mengancam hidupnya, maka ia beresiliensi melalui ritual Wulla Poddu yang merupakan sebuah ruang bagi seluruh suku-suku masyarakat yang terdapat di dalam Kampung untuk dapat dipersatukan kembali. Masyarakat dipersatukan tanpa mengenal golongan sosial, ras, terkhususnya aturan pemerintah dan agama yang seringkali mengikat masyarakat. Dalam hal ini ritual Wulla Poddu menjadi ritual yang bersifat terbuka di dalam ketidakpastian yang terjadi. Masyarakat mengalami resiliensi yang dalam suatu kapasitas sistem untuk menyerap gangguan yang terjadi di dalam komunitasnya dan menata ulang saat mengalami perubahan sehingga tetap mempertahankan fungsi, struktur, identitas dan saling menerima yang sama dasarnya.

\section{UCAPAN TERIMAKASIH}

Berterimakasih kepada kedua orang tua dan seluruh saudaraku atas semua dukungan moril dan materi selama kuliah di Universitas Kristen Satya Wacana.

\section{DAFTAR PUSTAKA}

Aisha, D. L. (2014). Hubungan Antara Religiusitas Dengan Resiliensi Pada Remaja di Panti Asuhan Keluarga Yatim Muhammadiyah Surakarta. Surakarta: Psikologi.

Bell, C. (1997). Ritual Prespective Dimensions. New York: Oxford University Press.

Bo'a, F. Y., \& Sri, H. R. W. (2019). Memahami Pancasila. Yogyakarta: Pustaka Pelajar.

Collins, R. (2004). Interaction Ritual Chains. New Jersey: Princeton University Press.

Creswell, J. W. (2010). Research Design: Pendekatan Kualitatif, Kuantitatif, dan Mixed. Yogyakarta: Pustaka Pelajar.

Djoru, N. (2017). Ritus Mangejing dan Integritas Sosial di Sumba: Memahami Makna Integritas Sosial Dalam Ritual Pasca Panen Mangejjing yang Dilaksanakan Oleh Masyarakat Kampung Waiwunga, Desa Makamenggit, Kabupaten Sumba TimurNTT. Universitas Kristen Satya Wacana.

Durkheim, E. (2011). The Elementary Forms Of The Religion Life: Sejarah Bentuk-Bentuk Agama Yang Paling Dasar. Yogyakarta: IRCISOD.

Grotberg, E. H. (2003). Resilience For Today: Gaining Strength From Adversity. Westport: Praeger Publishers.

Linkov, I., \& Palma-Oliveira, J. M. (2017). Resilience And Risk: Methods And Application In Environment, Cyber And Social Domains. Portugal: Springer. 
Berlian Rambu Pesi Kondi, Rama Tulus Pilakoannu \& Izak Y. M. Lattu, Ritual Wulla Poddu Sebagai

Moleong, L. J. (1991). Metodologi Penelitian Kualitatif. Yogyakarta: Gajah Mada University Press.

Palekahelu, D. T. (2010). Marapu Kekuatan di Balik Kekeringan: Potret Masyarakat Wunga Kabupaten Sumba Timur Provinsi Nusa Tenggara Timur. Salatiga: Satya Wacana University Press.

Pilakoannu, R. T. (2017). Ritual- Ritual Seputar Hutan dan Ladang Sebagai Daya Lenting Masyarakat Dayak Meratus di Loksado. KRITIS, Jurnal Studi Pembangunan Interdisiplin, XXVI(2), 111-121. Retrieved from

https://www.uksw.edu/detail_post/news/c egah-penularan-corona-bilik-sterilisasiuksw-gunakan-disinfektan-alami

Reivich, K., \& Shatte, A. (2002). Seven Essential Skills For Overcoming Life's Inevitable Obtacles. New York: Random House.

Samiyono, D. (2010). Sedulur Sikep Struktur Sosial dan Agama Masyarakat Samin di Sukalila. Salatiga: Program Pascasarjana Sosiologi Agama Universitas Kristen Satya Wacana.

Sugiyono. (2007). Metode Penelitian Pendidikan Pendekatan Kuantitatif, Kualitatif dan R\&D. Bandung: Alfabeta.

Sutomo, S. (2014). Estetika Tarian Sara Dounda Dalam Masyarakat Adat Loli, Sebuah Pendekatan Linguistic Kebudayaan. Parole: Jurnal Pendidikan Bahasa Dan Sastra Indonesia, 4(2), 6-8.

Taka, P. E. (2016). Ta'no: Ritual Perlawanan Masyarakat Oenbit di Timor Tengah Utara Terhadap Penambangan PT. Elgary Resources Indonesia. Universitas Kristen Satya Wacana.

Walker, B., Holling, C. S., Carpenter, S. R., \& Kinzig, A. (2004). Orientation and dynamics of a vesicle in tank-treading motion in shear flow. Physical Review Letters, 9(2), 1-9. https://doi.org/10.1103/PhysRevLett.95.25 8101

Wellem, F. D. (2004). Injil dan Marapu. Jakarta: BPK Gunung Mulia.

Winangun, Y. W. W. (1991). Masyarakat Bebas Struktur: Liminalitas dari Komunitas Menurut Victor Turner. Yogyakarta: Kanisius. 